\title{
Vitamin D2 Measurement
}

National Cancer Institute

\section{Source}

National Cancer Institute. Vitamin D2 Measurement. NCI Thesaurus. Code C74904.

The determination of the amount of Vitamin D2 present in a sample. 